\title{
Tiempo y Medio Ambiente como ejes noticiosos en los informativos de TVE, Antena 3 y Telecinco
}

Marián Alonso González | malonsog@us.es

Instituto Politécnico de Viseu, Portugal

\section{Resumen}

\section{Palabras clave}

"Medio Ambiente"; "Meteorología";

"Noticias"; "Televisión”; "Tiempo

atmosférico",; "Periodismo”.

Sumario

1. Introducción

1.1. Periodismo, clima y medio ambiente. 2 .

Objetivo e hipótesis.

3. Metodología.

4. Resultados y discusión.

4.1. Lugar que ocupan las noticias en el informativo.

4.2. Clasificación de noticias sobre la base de su contenido.

4.3. Composición de las noticias.

5. Conclusiones.

6. Bibliografía.

7. Anexo.
Si hasta hace apenas una década, el tiempo y la previsión meteorológica ocupaban un espacio propio al final de los informativos, desde hace unos años forman parte indiscutible del conjunto de las informaciones diarias, llegando a tener un lugar destacado cuando adquiere dimensiones de catástrofes y desastres naturales. Inundaciones, olas de calor o temporales de viento y lluvia son causas evidentes del cambio climático, uno de los mayores motivos de preocupación para los españoles, por delante, incluso, de los conflictos armados. El presente estudio cuantifica el peso específico que este tipo de información posee dentro de los informativos televisivos de TVE1, Antena $3 \mathrm{y}$ Telecinco, en su franja de mediodía, poniendo de manifiesto la importancia que las tres cadenas otorgan a este tipo de noticias, sobre todo en su vertiente amarillista y catastrofista, aunque, bien es cierto, que se aprecia una incipiente, y aún débil tendencia, a transmitir estas noticias desde un punto de vista pedagógico que permita concienciar a los españoles en la necesidad de tomar medidas para paliar las consecuencias del cambio climático.

\section{Cómo citar este texto:}

Marián Alonso González (2020): Tiempo y medio ambiente como ejes noticiosos en los informativos de TVE. Antena 3 y Telecinco, en Miguel Hernández Communication Journal, Vol. 11 (2), pp. 315 a 336. Universidad Miguel Hernández, UMH (Elche-Alicante). DOI: http://dx.doi.org/10.21134/mhcj.v11i0.337 


\section{Weather and Environment as news axes in the news of TVE, Antena 3 and Telecinco}

Marián Alonso González | malonsog@us.es

Instituto Politécnico de Viseu, Portugal

\section{Abstract}

Keywords

"“Journalism"; "Environment"; "Meteorology";

"Weather"; "Television"; "News".

Summary

1. Introduction.

1.1. Journalism, weather and enviroment.

2. Objective and hypothesis.

3. Methodology.

4. Results and discussion.

4.1. Place that occupies the news.

4.2. Classification of news based on its content.

4.3. News composition.

5. Conclusions.

6. Bibliography.

7. Annex.
A decade ago, the weather and meteorology occupied their own space at the end of the news, for a few years they have been an unquestionable part of all the daily information, becoming a prominent place when it acquires dimensions of catastrophes and disasters natural. Floods, heat waves or wind and rainstorms are obvious causes of climate change, one of the main reasons for concern for Spaniards, even ahead of armed conflicts. The present study quantifies the specific weight that this type of information has within in TVE1, Antena 3 and Telecinco television news, in its Lunchtime

News, highlighting the importance that the three channels give to this type of news, especially in its yellowish and catastrophic aspect, although, it is true, that an incipient, and still weak tendency is appreciated, to transmit this news from a pedagogical point of view that allows the Spaniards to be aware of the need to take measures to mitigate the consequences of climate change.

\section{How to cite this text:}

Marián Alonso González (2020): Time and environment as news axes in TVE’s news. Antena 3 and Telecinco, in Miguel Hernández Communication Journal, Vol. 11 (2), pp. 315 a 336. Universidad Miguel Hernández, UMH (Elche-Alicante). DOI: http://dx.doi.org/10.21134/mhcj.v11i0.337 


\section{Introducción}

Más de 11.000 científicos han declarado recientemente la "emergencia climática". El informe, publicado en la revista Bioscience (2019), comienza indicando que los científicos tienen "la obligación moral de avisar con claridad a la humanidad de cualquier amenaza catastrófica”, y concreta seis medidas que, según sus autores, son necesarias para hacer frente a la amenaza del cambio climático y evitar un "incalculable sufrimiento humano" (Ripple et al., 2019).

Desde el punto de vista meteorológico, el cambio climático se observa en la variación de la radiación solar, modificación de los parámetros orbitales de la tierra (excentricidad, inclinación del eje con respecto a la eclíptica), movimientos de la corteza terrestre y la actividad volcánica (CMNUCC, 1992). Este cambio es producido por el denominado efecto invernadero que provoca el calentamiento global y la aparición de nuevos fenómenos atmosféricos, desconocidos hasta el momento o que se suceden con mayor frecuencia y virulencia, y que ha hecho que la información meteorológica se haya convertido en parte importante del flujo informativo que recibimos a diario.

Ola de calor, gota fría o ciclogénesis explosiva son algunos de los términos que hemos incorporado a nuestro vocabulario diario y que forman parte de nuestras conversaciones. Hoy, más que nunca, y gracias a las nuevas tecnologías de medición y predicción, así como a Internet, la meteorología está muy presente en nuestras vidas y ha dejado de ser el tema banal del que hablar en un ascensor, para convertirse en objeto de debate y preocupación por el futuro del planeta.

La radio fue desde sus inicios el medio de transmisión de la meteorología. Los primeros boletines meteorológicos se radiaron en 1905 desde una serie de barcos de las Fuerzas Navales norteamericanas (Maldonado, 2017). En Europa, los primeros datos meteorológicos se transmiten en 1910 junto a las señales horarias de la estación parisina de la Torre Eiffel. No obstante, habrá que esperar hasta 1922 para que se conviertan en información de utilidad gracias a las $B B C$ inglesa y la Berliner Runfuk alemana.

En España, la primera emisión meteorológica de carácter informativo la realiza Radio Ibérica que, junto a las señales horarias de las 11 de la noche, emite un boletín confeccionado diariamente por el Observatorio Central Meteorológico. No obstante, al carecer de licencia, se considera a Eduard Fonteserè el precursor de estas noticias en Radio Barcelona ${ }^{1}$, la primera en emitir todas las tardes, de lunes a sábado, la "Carta del tiempo", un comentario sobre el estado actual del tiempo. La previsión meteorológica tendría que esperar un año más, así el 1 de febrero de 1927 se inicia el "Servicio de Meteorología Agrícola" en los boletines de las 11 y las 21 horas.

La Guerra Civil supone un importante freno para la radiodifusión española, la cual se convierte en un elemento propagandístico más que informativo, es por ello que hasta mediados de la década de los 50 la meteorología no vuelve a adquirir protagonismo informativo, y lo hace de la mano de Mariano Medina, quien popularizó la información meteorológica gracias a sus intervenciones en radio y televisión.

Desde sus inicios, la televisión se convirtió en el medio más popular para transmitir la información del tiempo, ya que la mejora del grafismo contribuyó a incrementar el conocimiento de la meteorología en general y, por ende, hizo que aumentara "el interés por estas noticias" (Maldonado, 2017).

\footnotetext{
${ }^{1}$ La primera emisión se realiza el 2 de agosto de 1926.
} 
El 30 de octubre de 1956 aparece el primer mapa isobárico en pantalla y junto a él, Medina haciendo las oportunas indicaciones. Esta situación se mantuvo hasta 1983, cuando la Ley de Incompatibilidades afecta al espacio meteorológico, ya que Mariano Medina se ve obligado a abandonar TVE, lo que provoca que durante 3 años la información hidrometeorógica consistiera en la locución de una voz en off sobre un mapa significativo.

En 1986, con la aparición de la televisión matinal, se decide incorporar esta información al programa "Buenos Días", que se emitía a las 7 de la mañana. La dureza del trabajo, que exigía levantarse a las 4 de la madrugada, abre un proceso selectivo que supone la aparición en antena de uno de los rostros más conocidos de la meteorología española: José Antonio Maldonado.

En 1988, bajo la dirección de Pilar Miró, RTVE decide sacar "El Tiempo" de los telediarios convirtiéndolo en un programa independiente y con entidad propia, ya que los mapas previstos y las imágenes de satélites y radares consiguen aumentar la credibilidad de las predicciones y que "el espectador pueda relacionar su propia experiencia con lo que observa en las imágenes" (Maldonado, 2017).

Este formato continúa a día de hoy, siendo diferente, en contenido y duración, según las distintas cadenas. Así, en su franja de mediodía, que es la que nos ocupa en esta investigación, TVE ofrece de forma pormenorizada la previsión meteorológica del día siguiente, en el ámbito de España en general y por comunidades autónomas. Este espacio, cuya duración oscila entre los 11 y los 12 minutos, es conducido por Albert Barniol.

En Telecinco, se sigue un formato similar, centrado en la meteorología de la península en su conjunto. Con una duración de entre dos y tres minutos, el espacio está conducido por Laura Madueño.

Mención especial merece el espacio que dirige Roberto Brasero en Antena 3. "Tu Tiempo", con una duración media de 13 minutos, incluye meteorología, pero también otros temas vinculados como el medioambiente, la ecología, la fauna, astronomía o la salud.

\subsection{Periodismo, clima y medio ambiente}

Se suele definir el clima "como el estado medio del tiempo, o más rigurosamente, como una descripción estadística del tiempo en términos de valores medios" (Águila, 2016:43). Tanto la meteorología como la climatología estudian los flujos de energía en el seno de la atmósfera, de hecho, según Linés (2010), tanto el tiempo atmosférico como el clima es algo cambiante, nuevo cada día y dinámico, lo cual apoya la "idea del cambio como algo inseparable del clima" y nos conduce a la "dicotomía conceptual entre el cambio climático natural y el artificial".

El cambio climático como tema noticioso ha sufrido altibajos en la agenda de la comunicación debido a la naturaleza compleja del problema y a la necesidad de una cooperación de los medios para:

La búsqueda de una mínima alfabetización científica que permita a la sociedad entender su complejidad y los cambios en temas geográficos, económicos, políticos, ambientales y sociales que la ciencia está produciendo para evitar una inercia difícil de revertir (Águila, 2016:119).

Los medios de comunicación, conscientes de las demandas ciudadanas incluyen, de forma vez 
es más frecuente, la presencia de temas medioambientales en los informativos diarios. A ello ha contribuido la llegada de las televisiones privadas, el desarrollo de la especialización periodística y la expansión de Internet, pero también la aparición de situaciones inesperadas que generan preocupación en la colectividad, tal es el caso de sequías, inundaciones, incendios forestales, etc., que son vinculados a una conciencia ecológica definida "más como un sentimiento que como una argumentación racional” (Kindelán, 2013:118).

Es por ello que el cambio climático es un concepto usado de manera recurrente por los medios de comunicación con relación a:

Predicciones alarmistas y tintes sensacionalistas que han conseguido la vulgarización del conocimiento sobre el tema prescindiendo de una información con un enfoque y tratamiento adecuado, dejando de lado la exageración y el dramatismo en exceso (Sánchez, Morales \& Cáceres, 2012: 115).

En España, la relación entre periodismo, clima y medio ambiente ha pasado por dos etapas diferenciadas, una primera, vinculada al movimiento ecologista y una segunda desvinculada de dicho movimiento social y concentrada en la profesionalidad de la información pero que, al mismo tiempo, a través de la publicidad refleja modelos de vida que incitan al consumo de recursos de forma indiscriminada y, por ende, a patrones contrarios a la sostenibilidad (Fernández Reyes, 2010).

Hoy en día, no es fácil comprender la gran cantidad de información que existe en torno al medio ambiente y el cambio climático, es por ello que la comunicación cobra un papel relevante dentro de la configuración del imaginario colectivo, y se convierte en sujeto activo de la lectura psicosocial del mundo propuesta por Moscovici (1985).

Las representaciones facilitan la incorporación de nuevos elementos a la vida cotidiana, renovando los esquemas o visiones particulares del mundo y, con ello, provocan el dinamismo de los grupos sociales y los individuos que los componen (Rubira-García, Puebla-Martínez \& Gelado-Marcos, 2018:7) y es ahí precisamente donde los medios de comunicación, como principal ventana de acceso a la realidad ambiental, deben ejercer un importante papel en el avance de la información y la sensibilización ambiental (Meira, 2008).

Es por ello, que se hace necesario conocer qué se cuenta y cómo se transmite para:

Entender las actitudes sociales respecto a asuntos de gran calado como el cambio climático partiendo de la base de que un correcto tratamiento informativo fomentará un mejor conocimiento de los temas ecológicos, una mayor concienciación ambiental social, e incidirá en la transformación de valores, actitudes y comportamientos sostenibles (Mercado, 2013: 123).

Sin embargo, los medios de comunicación, en su cometido de mostrar la realidad emplean sus propios criterios de selección y jerarquización para alimentar espacios y flujos públicos de información de gran alcance, en los que las catástrofes aparecen con toda su contundencia desestabilizadora (Teso y Lozano, 2018).

De hecho, el cambio climático como objeto noticioso es abordado por los medios de comunicación porque "lo marca la agenda política y porque los comunicados o actos públicos convocados y emitidos por la Comunidad Científica convierten a este fenómeno en noticia del 
día" (Teso, 2010).

Si tenemos en cuenta que el pensamiento natural o sentido común viene determinado por "la información, el conocimiento y los modelos de pensamiento que recibimos y transmitimos a través de la tradición, la educación y la comunicación social" (Rubira-García, Puebla-Martínez \& Gelado-Marcos, 2018:4), la cobertura mediática de los temas ambientales y la especialización periodística exigen al informador una actitud responsable: "un periodismo en profundidad que ha de fundamentarse en una documentación exhaustiva, narración de antecedentes, consecuencias y actores implicados, análisis del hecho ambiental e inserción de acontecimientos en el contexto adecuado" (Bachetta, 2002).

En esta misma línea se pronuncia Boykoff (2010), para quien los mass media son agentes clave que dan forma a los discursos científicos y políticos sobre el cambio climático, contribuyendo a modelar las respuestas humanas ante este fenómeno. Es por ello que deben apostar decididamente por una divulgación que aúne el rigor científico y la responsabilidad social y que supere el modelo comunicativo que centra el cambio climático en el tratamiento informativo de noticias relativas a olas de frío y calor, inundaciones, grandes tormentas o sequías (Heras, 2013).

\section{Objetivos e hipótesis}

La cobertura de emergencias y desastres naturales tiene relación con el periodismo científico, el cual "debe favorecer el tratamiento transversal de todas las noticias a fin de ayudar al receptor a entender correctamente el fenómeno" (OPS, 2011: 14), es por ello, que el presente estudio tiene como objetivo conocer el tipo de información que los informativos de televisión ofrecen con relación al clima y al medio ambiente en España.

En este sentido, pretendemos realizar un análisis de las noticias emitidas por las tres cadenas televisivas más importantes de España, a través de diferentes variables y categorías, para identificar los rasgos esenciales que atañen a la cobertura informativa del tiempo como tema relevante de la agenda setting de los medios.

Nuestra hipótesis de partida es que los informativos tienen a los desastres naturales como epicentro informativo y se centran sólo en ciertos aspectos del problema del cambio climático, en vez de explicar sus causas, impactos y soluciones a fin de contribuir a concienciar a la sociedad sobre la necesidad de proteger el medio ambiente.

\section{Metodología}

El presente estudio se basa en un estudio de contenido de la cobertura mediática que los informativos de televisión otorgan a la información relativa al tiempo y al medio ambiente. Para la consecución de los objetivos hemos realizado el seguimiento de los noticieros de mediodía de las cadenas privadas Antena 3 y Telecinco, y de la pública TVE1, por ser, según datos del último EGM, los espacios que un mayor número de espectadores congregan (AIMC, 2019). En este sentido, Informativos Telecinco mantiene el liderato (15,3\%), seguido de Antena 3, que crece hasta el 15,2\%, mientras que TVE1, experimenta un leve crecimiento hasta situarse en el 12,1\% (Barlovento, 2019).

A fin de obtener unos resultados lo más completos posibles hemos procedido al estudio de las noticias emitidas a lo largo de 22 días, repartidos en dos periodos de 11 días, y con una diferencia entre ambos de una quincena, ya que la naturaleza caótica de la atmósfera y los modelos de 
predicción numérica del tiempo limitan su capacidad a alcances comprendidos entre los 10 y los 14 días (Aemet, 2019).

Este intervalo temporal tiene por objeto que la existencia de un fenómeno meteorológico concreto no interfiera, e incluso llegue a alterar, el cómputo de tiempo total destinado por las cadenas de nuestro estudio a la información medioambiental y meteorológica. Los periodos elegidos son los comprendidos entre el 16 y 26 de septiembre y entre el 7 y el 17 de octubre de 2019, ambos incluidos, a fin de que los datos obtenidos fueran de actualidad y por considerar que se trata de un periodo suficiente para poder desarrollar un correcto estudio longitudinal.

En total, hemos analizado 204 noticias, en base a los siguientes parámetros:

1. Duración individual de las noticias y peso específico que este tipo de información posee dentro del conjunto del noticiero, a fin de determinar, la "preeminencia de los temas abordados como noticia sobre otros que no lo son, destacando algunos aspectos de la realidad para hacerlos más notorios" (Teso, 2016: 53).

2. Lugar jerárquico que dichas noticias ocupan en el conjunto del informativo.

3. Composiciones encontradas en las noticias: presentador, presentador + colas, presentador + pieza, presentador + entrevista, presentador + conexión en directo y presentador + conexión en directo + pieza.

4. Número de totales que se incluyen en las noticias y clasificación de su procedencia (afectados, expertos, políticos y otros), a fin de determinar qué actores son más importantes a la hora de relatar la actualidad informativa.

5. Análisis del contenido de las noticias. Para ello, y a falta de una clasificación previa, las hemos encuadrado en tres categorías: meteorología y previsión, riesgo o catastrofismo y sostenibilidad ambiental (Entman, 1993, Scheufele, 1999; Semetko y Valkenburg, 2000; Tankard, 2001; Vicente y López, 2009). Las primeras hacen referencia al tiempo en existente en España y sus comunidades autónomas, las segundas son aquella que tratan esas noticias como si de un suceso se tratase y las últimas son las que intentan adaptar el mensaje de la comunidad científica a una población cada vez más interesada en los efectos y consecuencias del cambio climático.

\section{Resultados y discusión}

A lo largo del presente estudio hemos analizado un total de 204 noticias relacionadas con la meteorología y el medio ambiente y que han sido emitidas en los informativos de mediodía de la cadena pública TVE y de las privadas Antena 3 y Telecinco.

Por cadenas, destacan TVE y Telecinco, ambas con 75 noticias, mientras que Antena 3, sólo emitió 54 (Ver Gráfico 1). 
Gráfico 1. Número total de noticias emitidas. Fuente propia.

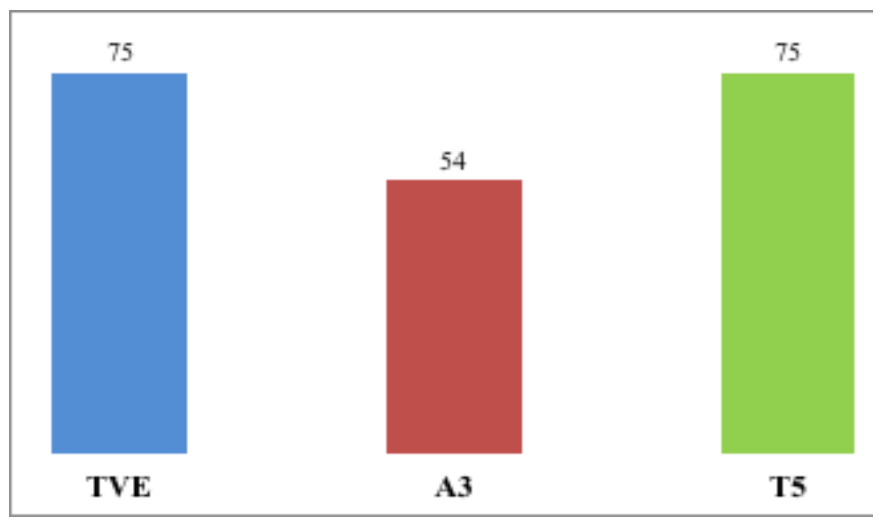

Por periodos, resulta más prolífico el flujo informativo del primer periodo, llegándose a contabilizar 115 de las 204 noticias analizadas (Ver Tabla 1). Ello responde a la máxima de actualidad informativa respecto a la gota fría o $\mathrm{DANA}^{2}$, un fenómeno meteorológico de principios de otoño que afecta, fundamentalmente, a la costa este e Islas Baleares.

Tabla 1. Noticias analizadas por cadenas

\begin{tabular}{|l|c|c|c|}
\hline & TVE & A3 & T5 \\
\hline Periodo 1 & 42 & 32 & 40 \\
\hline Periodo 2 & 33 & 21 & 38 \\
\hline
\end{tabular}

Fuente: Elaboración propia

Durante el primer periodo, TVE ha destinado una media diaria de casi 18 minutos a informar sobre el tiempo y el medioambiente (17'51"), seguido de Telecinco (12'17”) y Antena 3 (11'01”).

No obstante, si tenemos en cuenta que el informativo de TVE tiene una duración de 53 minutos, frente a los 34 que duran los de Telecinco y Antena 3, comprobamos que atendiendo al peso específico que estas noticias poseen en el conjunto del informativo las tres cadenas presentan cifras muy similares. Así, Telecinco es la cadena que mayor tiempo destina a este tipo de informaciones, el 35,7\% del total de su noticiero (Ver Gráfico 2), seguida por TVE (33\%) y Antena 3 (32\%).

Telecinco vuelve a liderar el segundo periodo (44,3\%). En esta ocasión, saca más de 20 puntos de ventaja a TVE (24,7\%), la cual dobla a Antena 3 que destina solo el 12,6\% de sus informaciones a esta materia.

\footnotetext{
${ }^{2}$ Acrónimo de Depresión Atmosférica Aislada en Niveles Altos.
} 
Gráfico 2. Tiempo destinado por las cadenas a los temas medioambientales.

\section{Periodo 1}

Periodo 2

$50,00 \%$

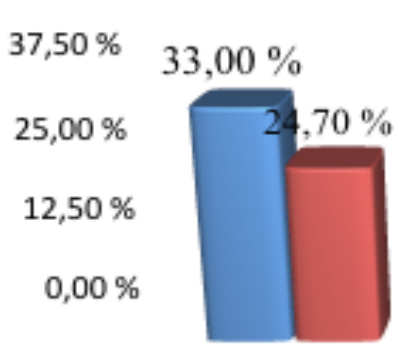

TVE

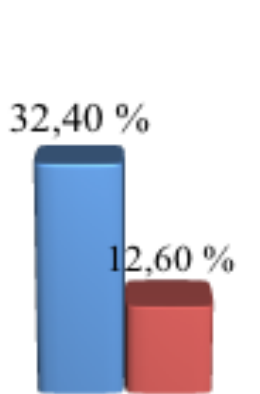

A3

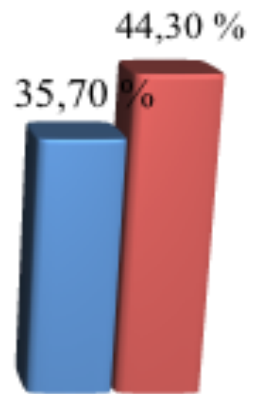

T5

Fuente: Elaboración propia

\subsection{Procedimiento}

Las noticias relativas al tiempo y al medioambiente suelen figurar en el sumario. Como puede apreciarse en los siguientes gráficos $(3$ y 4), un total de 51 noticias han ocupado los sumarios de los informativos de mediodía, siendo éstos más abundantes en la cadena pública TVE (21), seguida de Telecinco (18) y Antena 3 (12).

De igual forma, resulta interesante señalar que la previsión meteorológica, pese a contar con un espacio propio e independiente al final del telediario, también se convierte en una noticia más dentro del informativo, de manera, que es frecuente que los presentadores den paso, dentro del propio plató, al meteorólogo para que sea éste quien realice una valoración de la realidad atmosférica. Esta situación la hemos detectado en 20 ocasiones, siendo más frecuente en TVE (11), mientras que en Antena 3 sólo se da en 2 días (Ver Gráficos 3 y 4).

Gráfico 3. Lugar que ocupan las informaciones durante el primer periodo

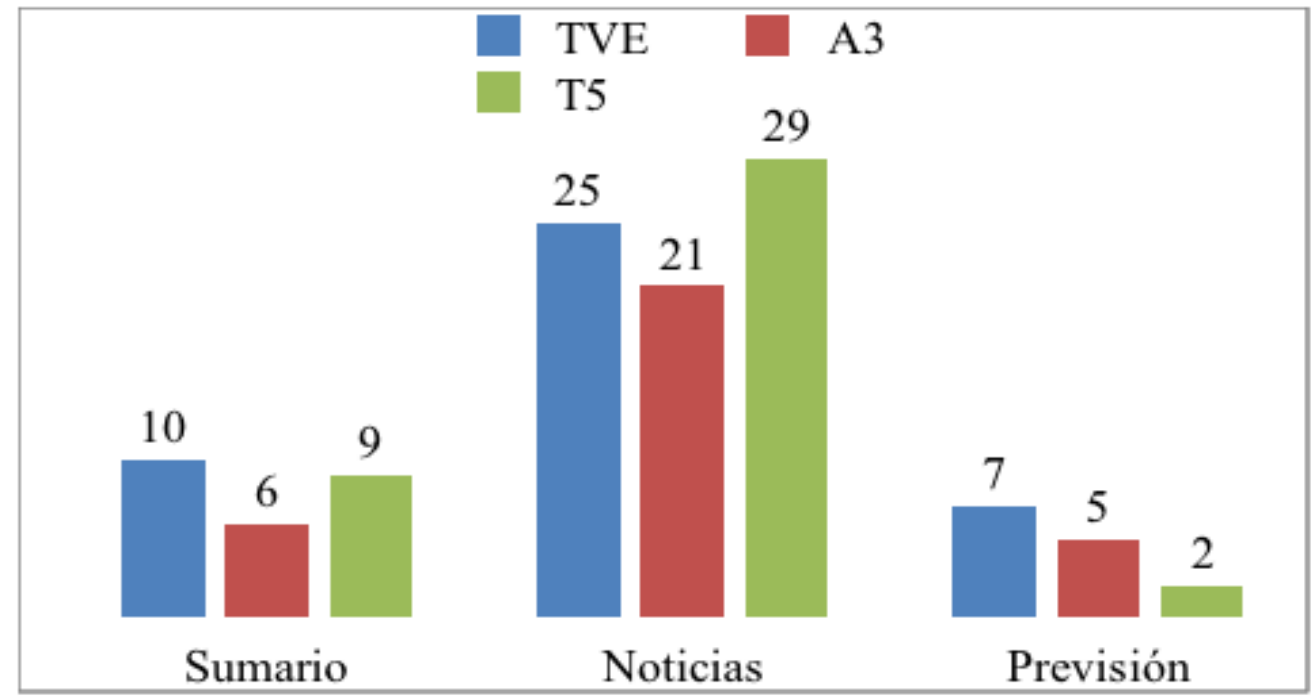

Fuente: Elaboración propia 


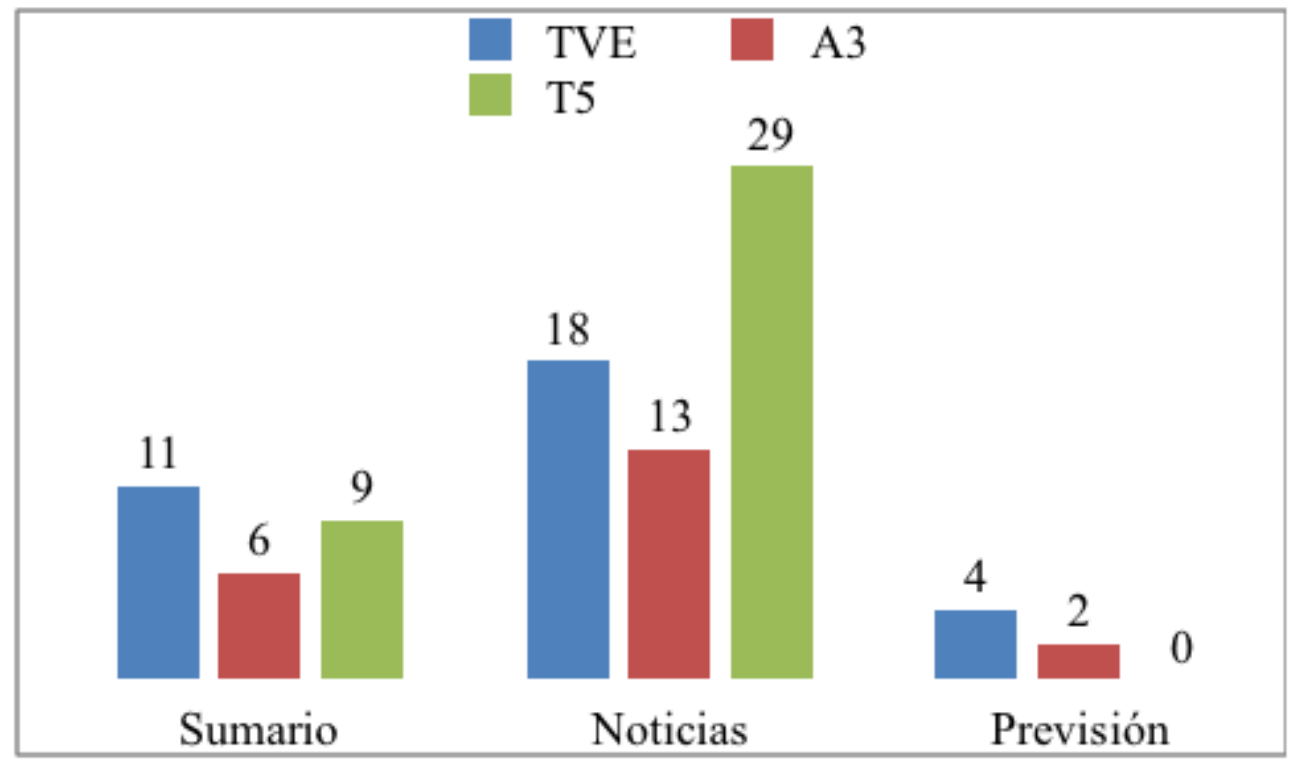

Fuente: Elaboración propia

Pese a que las noticias de carácter medioambiental y meteorológico son destacadas en el sumario, su relevancia no se corresponde con el lugar que ocupan en el minutado final de la escaleta. Así pues, en el caso de TVE, sólo el 5\% de las noticias se emite durante los primeros veinte minutos, el 31\% entre los minutos 20 y 30 y el 64\% en los últimos 13 minutos del informativo.

Esta situación es bastante homogénea en ambos periodos, de hecho, durante el mes de septiembre sólo dos noticias se emiten en los primeros diez minutos del informativo, se trata de las relativas a la Cumbre del Clima de Nueva York y a la mayor virulencia del fenómeno DANA. El resto, como puede apreciarse en el Gráfico 5, suele darse en su mayoría a partir de la segunda mitad del informativo, hasta un total de 39 noticias se emiten a partir del minuto 20 de programa.

Como ya hemos adelantado, esta situación vuelve a repetirse durante el segundo periodo de estudio, dónde observamos que 27 de las 33 noticias, es decir, el 81,8\% de las informaciones emitidas se ubica a partir del minuto 20 (Ver Gráfico 6).

El fenómeno inverso lo observamos en Telecinco, dónde el 40\% de las noticias se emite en los primeros 20 minutos de programa, y el 38\% entre los minutos 20 y 30. Sólo el 22\% de sus informaciones ocupa el tramo final del informativo.

Por periodos, es durante los días 16 y 26 de septiembre, cuando se otorga mayor relevancia a estas noticias, de hecho, el $60 \%$ de las noticias se emite en los primeros 20 minutos de informativo, y el 35\% entre los minutos 20 y 30. La situación se invierte durante el segundo periodo de estudio, cayendo hasta un $18,4 \%$ las noticias emitidas durante el primer bloque.

En un punto intermedio se sitúa Antena 3. El 28\% de sus noticias ocupa los primeros veinte minutos del noticiero, el 30\% se emite entre los minutos 20 y 30, y el 42\% en los últimos diez minutos del informativo. Durante el primer periodo, como puede apreciarse en el Gráfico 5, el 
$37,5 \%$ de las noticias ocupa la primera mitad del informativo y otro $37,5 \%$ entre los minutos 20 y 30.

En la segunda etapa, sólo una noticia abre el informativo de Antena 3, la correspondiente al informe de "Emergencia Climática en España", el 14,28\% se emite en los primeros 20 minutos, mientras que el 66,6\% ocupa los últimos 10 minutos del informativo (Ver Gráfico 6).

Gráfico 5. Minutado de las noticias durante el primer periodo.

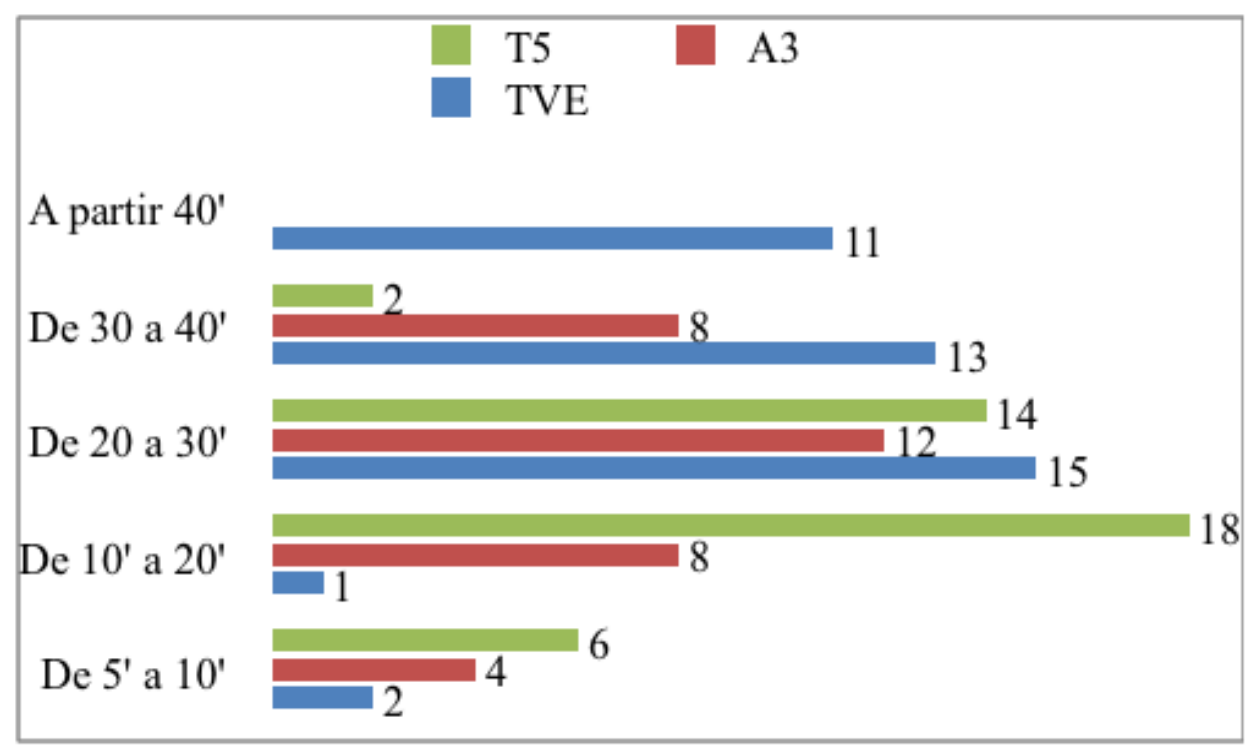

Fuente: Elaboración propia

Gráfico 6. Minutado de las noticias durante el segundo periodo.

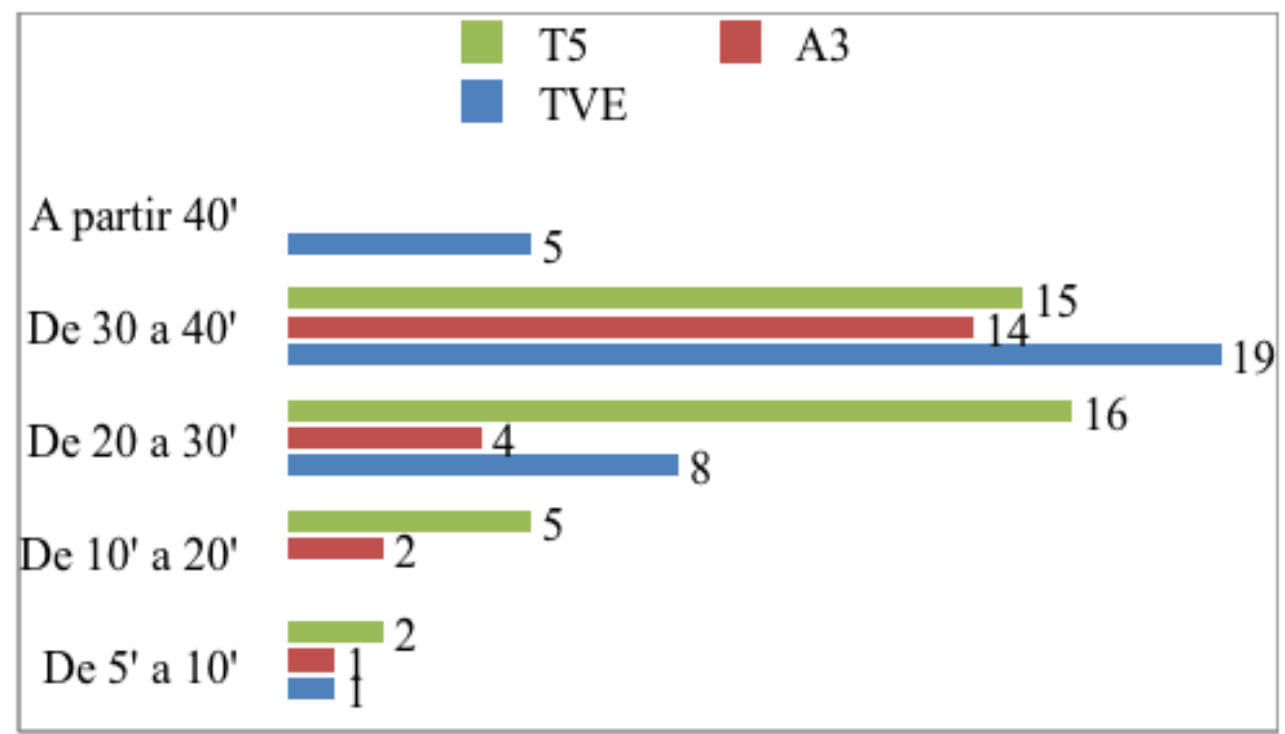

Fuente: Elaboración propia 
Debido al fenómeno atmosférico DANA, el grueso informativo está relacionado con la gota fría y los destrozos que ha provocado en Murcia, Albacete y Cataluña. De las 57 noticias analizadas, solo 3 ofrecen información objetiva del tiempo, la mayoría está enfocada a la catástrofe asociada al temporal de lluvia y viento, siendo este tipo de información mayor en Telecinco (21), seguido a corta distancia por TVE y Antena 3, ambas con 18.

Las noticias relacionadas con el medioambiente son más frecuentes en TVE y Telecinco (12 y 10, respectivamente) y hacen alusión a la Cumbre del Clima de la ONU en Nueva York, así como a las protestas juveniles organizadas con motivo de este encuentro. Estas noticias se dan, principalmente, entre los días 21 y 24 de septiembre como resumen del evento, en jornadas posteriores se ofrecen noticias relacionadas con el calentamiento global en España y cómo preocupa este tema a los españoles a raíz de la publicación de un informe dado a conocer el 23 de septiembre.

Por su parte, durante este primer periodo, las noticias relativas al tiempo hacen alusión a la llegada del otoño y de las inusuales temperaturas veraniegas que aún persisten, siendo éstas más abundantes en Telecinco (7), seguida de TVE (5) y Antena 3 (4) (Ver Gráfico 7).

Gráfico 7. Periodo 1. Clasificación noticias sobre la base de su contenido.

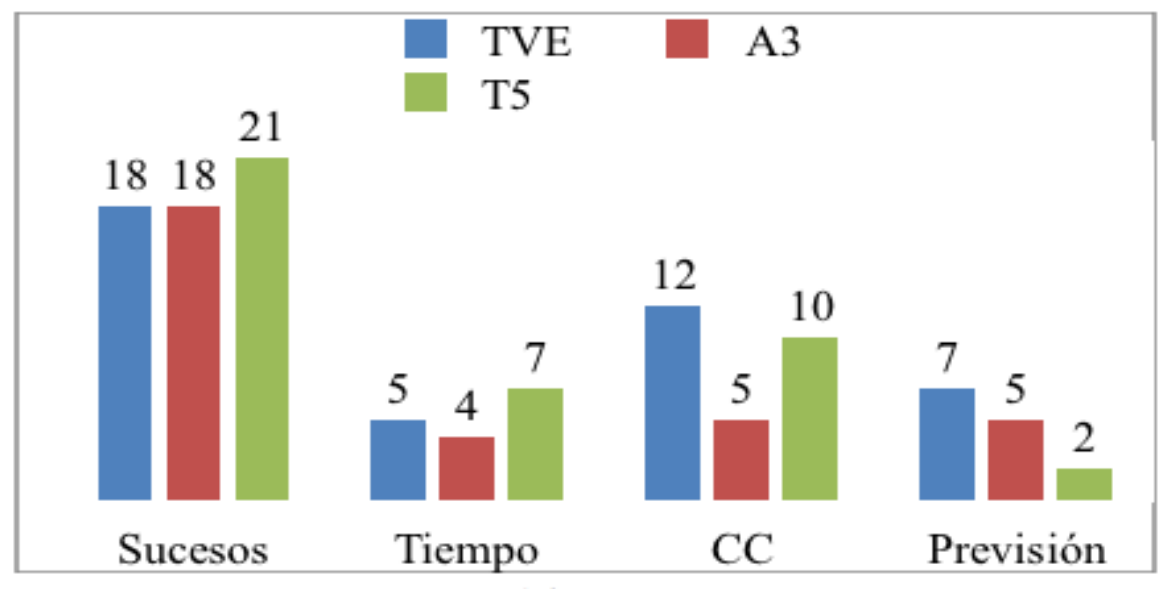

Fuente: Elaboración propia

El segundo periodo es más tranquilo meteorológicamente hablando, las temperaturas y el clima se mantienen estables hasta el 14 de octubre, cuando llegan las precipitaciones al norte de España y con ellas una bajada significativa de las temperaturas, ello se refleja en un descenso del número de noticias relativas al asunto de nuestro estudio, 90, frente a las 114 del primer periodo.

Como puede apreciarse en el Gráfico 8, el cambio meteorológico se deja sentir, especialmente, en Telecinco (10) y TVE (8), quienes incorporan a sus informativos noticias relativas al veroño ${ }^{3}$ y las lluvias, temas que se repiten en las previsiones de TVE (4) y Antena 3 (2).

Las noticias relativas a los sucesos y catástrofes relacionadas con los fenómenos meteorológicos siguen ocupando un grueso importante del informativo (38), y se centran fundamentalmente en el Tifón de Japón, las inundaciones de Londres, el aniversario de las riadas de Mallorca y las consecuencias de la gota fría analizada en el primer periodo. Como puede apreciarse en el Gráfico

\footnotetext{
${ }^{3}$ Acrónimo de carácter coloquial que fusiona parte de los nombres de las estaciones de verano y otoño. Se refiere a los meses de otoño en los que siguen las temperaturas altas y la sequedad propias del verano (Fundéu, 2017)
} 
6, las cantidades son muy similares entre las 3 cadenas, ocupando la primera posición Telecinco (15), seguida de TVE (12) y Antena 3 (11).

Por su parte, las noticias de índole medioambiental se siguen dando en igual medida (27), siendo más abundantes en Telecinco (13), seguida de TVE (9). Llama la atención que Antena 3 sólo ofrezca 5 noticias relacionadas con el cambio climático durante estos once días y que estén relacionadas directamente con la falta de lluvias y con los efectos que las mismas han provocado.

Gráfico 8. Periodo 2. Clasificación noticias sobre la base de su contenido.

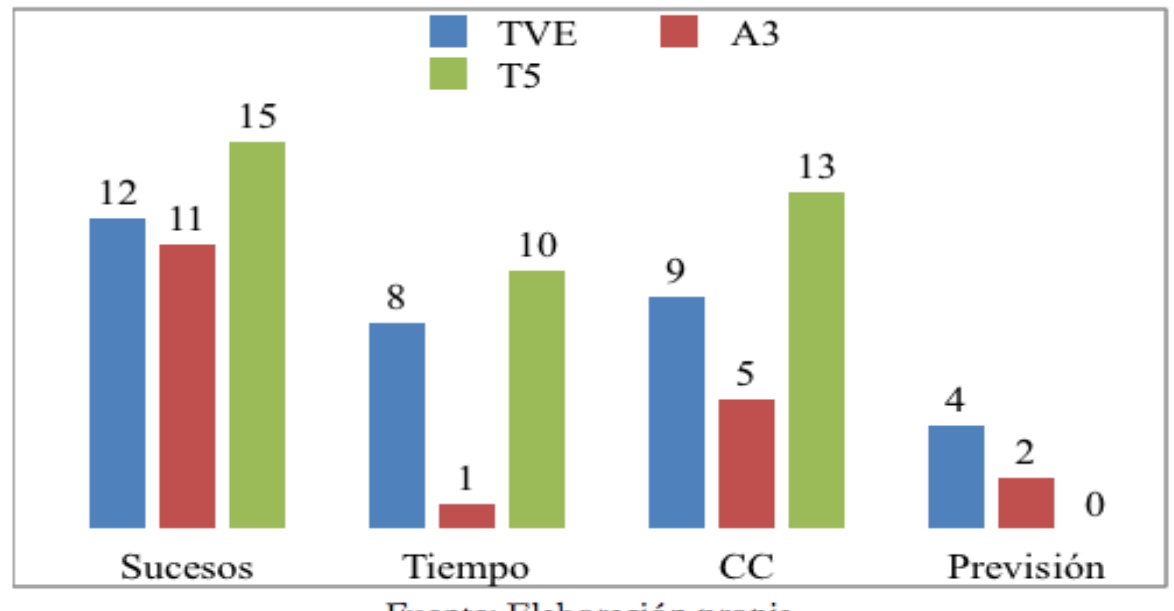

Fuente: Elaboración propia

TVE es la cadena que mayor tiempo destina a las noticias relacionadas con el medioambiente, un total de 47 minutos (47'46”), seguida de Telecinco (27'24') y Antena 3 (15'32') (Ver Tabla 2).

Mientras que Telecinco dedica un tiempo similar en ambos periodos al contenido medioambiental, abriendo el abanico a temas como la rebelión verde, la contaminación, la presencia de plásticos en las playas y el desastre ecológico del Mar Menor; Antena 3 centra sus informaciones en la cobertura de la Cumbre de Nueva York.

La actualidad informativa es la que prima en la cadena de Atresmedia. Si durante el primer periodo destina 11 minutos a este tipo de noticias, en el segundo, esta información es meramente testimonial (4'31") y está referida, exclusivamente, a un informe sobre el efecto del calentamiento global en España.

TVE, por su parte, duplica el tiempo invertido en medioambiente durante el segundo periodo, haciéndose eco del calentamiento global, el estado de los embalses por la sequía, y la subida de la temperatura del mar Mediterráneo y sus efectos inmediatos.

Tabla 2. Tiempo dedicado por las cadenas a informar sobre medioambiente.

\begin{tabular}{|c|c|c|c|}
\cline { 2 - 4 } \multicolumn{1}{c|}{} & Periodo 1 & Periodo 2 & Total \\
\hline TVE & $17^{\prime} 51^{\prime \prime}$ & $29^{\prime} 55^{\prime \prime}$ & $47^{\prime} 46^{\prime \prime}$ \\
\hline A3 & $11^{\prime} 11^{\prime}$ & $4^{\prime} 31^{\prime}$ & $15^{\prime} 32^{\prime \prime}$ \\
\hline T5 & $12^{\prime} 17^{\prime \prime}$ & $15^{\prime} 07^{\prime \prime}$ & $27^{\prime} 24^{\prime \prime}$ \\
\hline
\end{tabular}

Fuente: Elaboración propia 


\subsection{Composición de las noticias}

Respecto a la composición de las noticias en función de las posibles combinaciones de los elementos que definen su estructura y formato, destacar que dos formatos acaparan el $55 \%$ de las mismas. Las piezas de "presentador + conexión en directo" y "presentador + colas", constituyen las fórmulas más empleadas, $32 \%$ y 23\%, respectivamente. Le sigue el formato de "presentador + pieza" (15\%) y "presentador + colas+ conexión en directo" (13\%). (Ver Gráfico 9).

Gráfico 9. Porcentaje de fórmulas más utilizadas en las noticias.

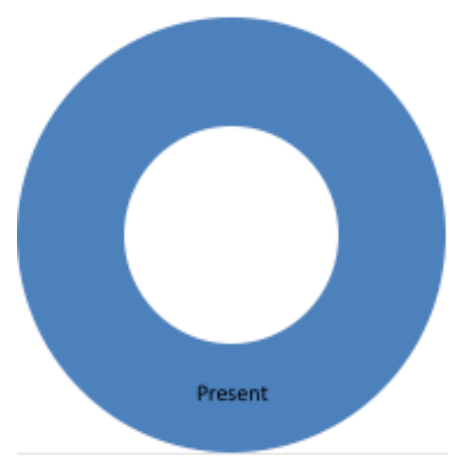

Del análisis realizado, dos aspectos llaman nuestra atención, por una parte, que las noticias dadas únicamente por un presentador se corresponden exclusivamente con aquellas informaciones ubicadas en el sumario, y el hecho que no haya ninguna noticia que se enmarque en el formato de "presentador + entrevista".

La entrevista es descartada por las tres cadenas, limitando su uso a la extracción de totales que refuerzan el valor informativo de las noticias y que se usan, prioritariamente, en el formato de "presentador + pieza", compuesto por una introducción de la noticia realizada en plató y en directo por el presentador/a del informativo y la pieza grabada y previamente editada.

A lo largo del presente análisis hemos encontrado 610 totales, lo que supone una media de casi 3 totales por noticia $(2,96)$. Tan sólo un 10,6\% de las noticias emitidas no incluyen ninguna declaración, lo cual es indicativo de una elevada pluralidad de opiniones en sus contenidos. Estos totales corresponden a afectados $(60 \%)$, expertos $(23 \%)$ y políticos $(9 \%)$ y otros $(5 \%)$.

Por cadenas, TVE es la que registra un mayor número de totales, 258, seguida de Telecinco, con 236. Antena 3, con 116 totales, es la que menos posibilidades ofrece de encontrar posiciones que confronten las afirmaciones de los declarantes.

Dentro del formato "presentador + pieza" hemos incluido también los reportajes. Estamos ante un reportaje cuando el hecho noticioso es desarrollado con amplitud, incorporando a los datos el relato y las opiniones de los protagonistas, de forma que se puede profundizar en las causas y consecuencias de la información. Estos se ciñen en exclusiva a temas medioambientales, siendo TVE la que más ha emitido (10), seguida de Antena 3 (9) y Telecinco (6).

Como la mayoría de las noticias están relacionadas con la climatología y las catástrofes asociadas a la misma, son frecuentes las conexiones en directo con aquellos puntos en los que el suceso ha 
tenido una mayor incidencia, es entonces cuando se emplea en mayor medida la crónica, un género que permite al periodista, desde el lugar de los hechos, acercar al espectador al acontecimiento, aportando proximidad al hecho narrado e incrementando la veracidad y credibilidad de lo contado.

En total, hemos registrado 122 conexiones en directo, de las cuales, el $40 \%$ corresponden a Telecinco, seguida de TVE (32\%) y Antena 3 (28\%) (Ver Gráfico 10).

Por periodos, éstas han sido más frecuentes entre los días 16 y 26 de septiembre, registrándose hasta un total de 77, y presentando proporciones muy similares las tres cadenas 36,5\% Telecinco, $32,4 \%$ Antena 3 y $31,1 \%$ TVE. En el segundo periodo se observa una caída importante de las conexiones en directo, de 77 a 45, ello es debido a una mayor estabilidad meteorológica. Por cadenas, lidera Telecinco (47\%), seguida de TVE (33\%) y Antena 3 (20\%) (Ver Gráfico 10).

Gráfico 10. Conexiones en directo realizadas por las cadenas en ambos periodos.

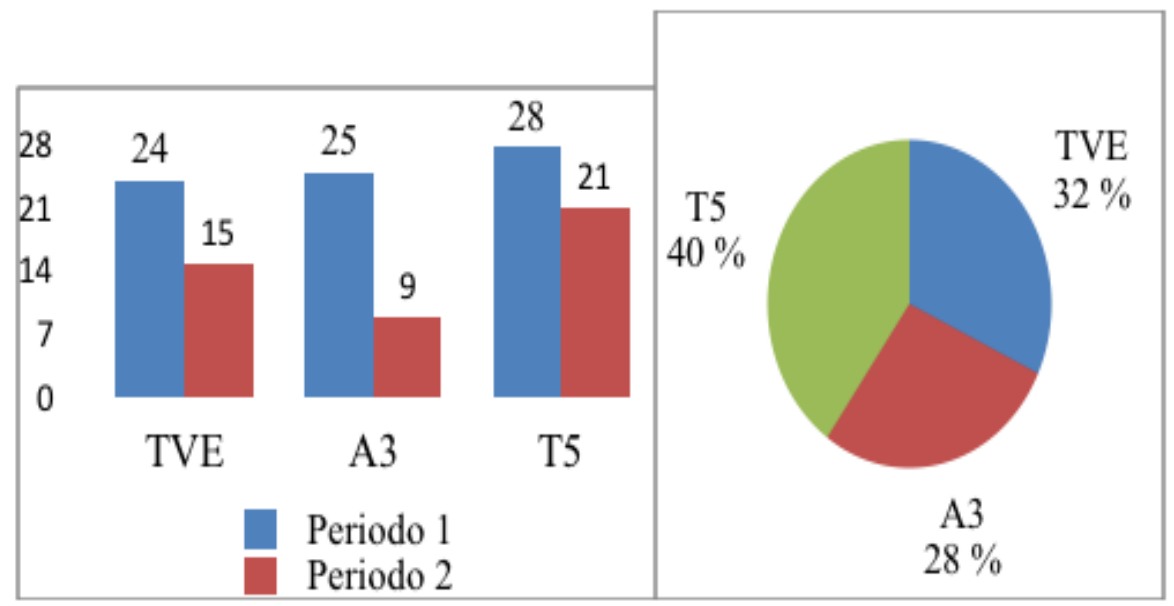

Fuente propia

En ocasiones, las cadenas deciden enviar a más de un periodista de apoyo a fin de enriquecer las perspectivas informativas. Este fenómeno lo hemos observado en 8 noticias de Telecinco, 7 en Antena 3 y 5 en TVE. Lo más habitual es la conexión con dos periodistas desplazados, no obstante, con motivo del fenómeno DANA las cadenas privadas han incrementado sus esfuerzos por llegar a todos los puntos afectados, así Antena 3 cuenta con hasta cuatro corresponsales en varias de sus noticias, mientras que Telecinco conecta por lo general con 3 periodistas desplazados, habiéndose detectado hasta 6 conexiones en una misma información.

Las noticias con colas, aquellas que comienzan con el presentador dando pie a la noticia para, a continuación, relatar lo acontecido en off sobre una secuencia de imágenes que tienen una función referencial de lo narrado; representan el $23 \%$ del total, seguidas por el formato "presentador + pieza", utilizado en el $15 \%$ de las ocasiones.

Por cadenas destaca Telecinco, que utiliza este formato en el 51\% de sus noticias. De hecho, es el modo más utilizado para informar sobre acontecimientos y catástrofes meteorológicas ocurridas fuera de España, tal es el caso del tifón de Japón, las lluvias de Londres o los incendios de Australia. Para ello se recurre a las imágenes proporcionadas por agencias internacionales y la narración de 
sus presentadores.

Como puede observarse en los Gráficos 11 y 12, durante el primer periodo el formato preferido por las tres cadenas es el formado por "presentador + conexión en directo", seguido del "presentador + pieza". Sin embargo, en el segundo periodo son más abundantes los formatos "presentador + colas", en un 34,8\% de las ocasiones; y "presentador + conexión directo" (31,5\%), ello es debido a que son más abundantes las noticias relativas a catástrofes internacionales.

Gráfico 11. Composiciones encontradas en las noticias durante el primer periodo.

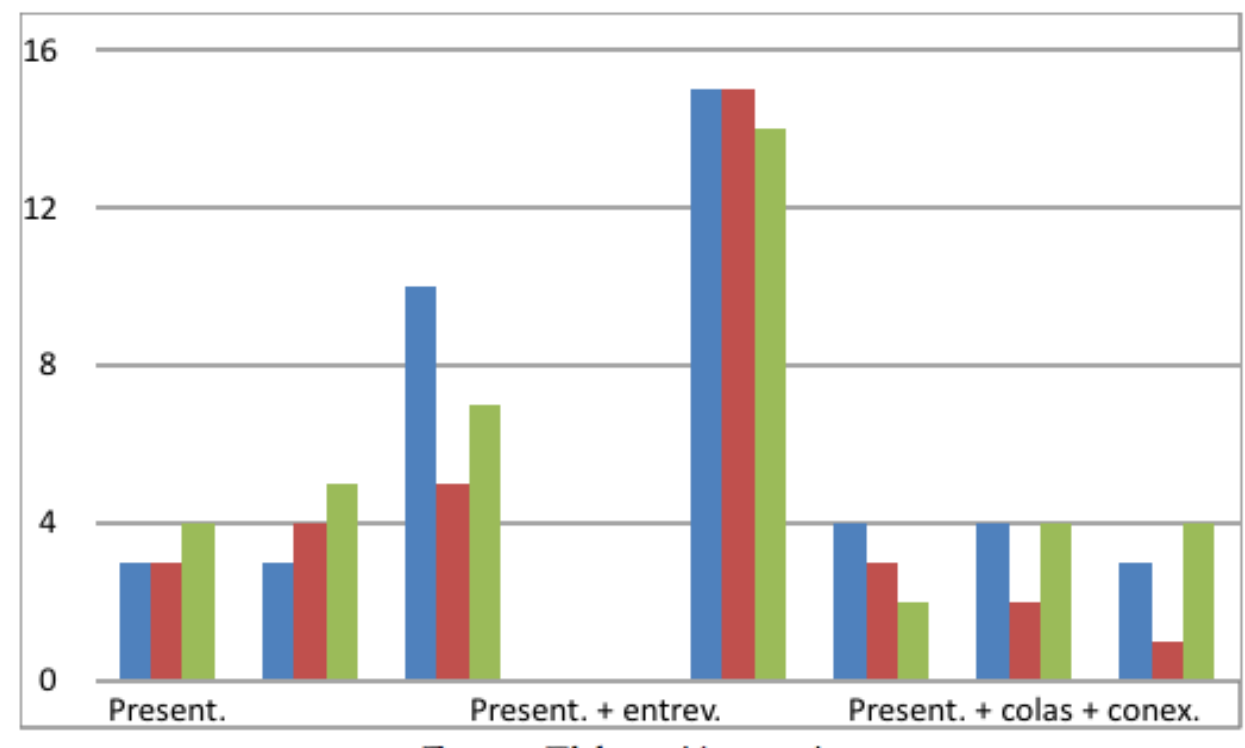

Fuente: Elaboración propia

Gráfico 12. Composiciones encontradas en las noticias durante el primer periodo.

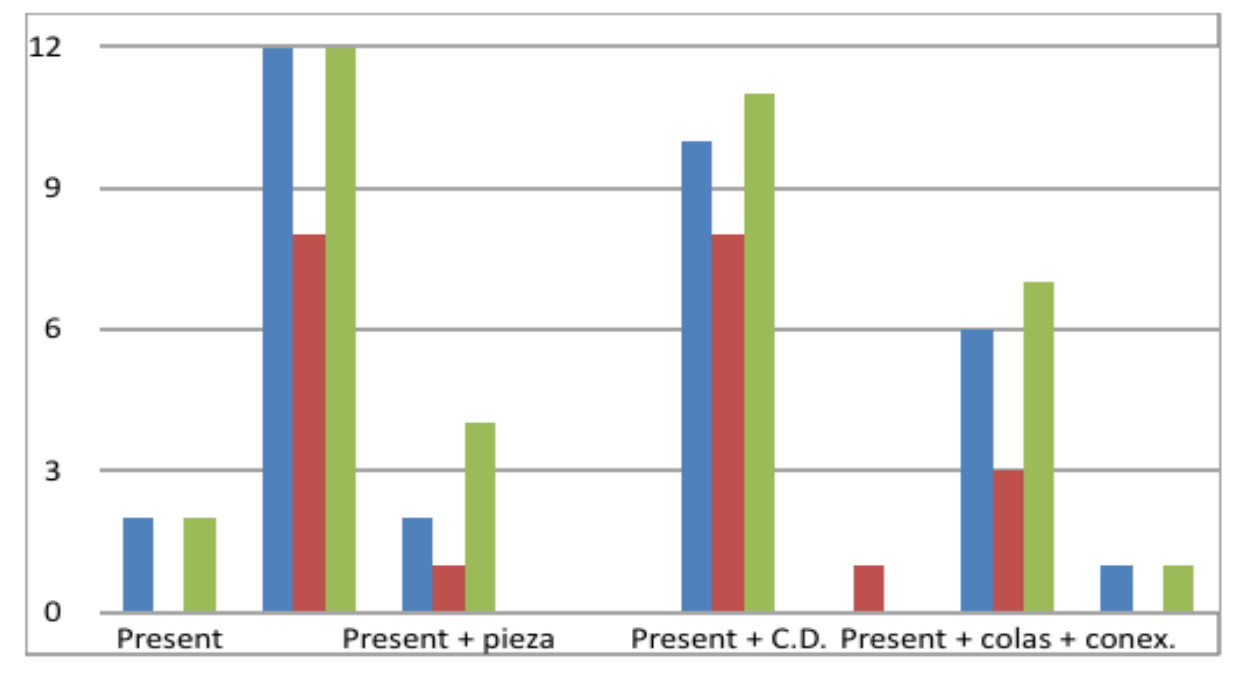

Fuente propia 


\section{Conclusiones}

La información hidrometeorológica y medioambiental ocupa gran parte de los contenidos de los telediarios de las tres cadenas objeto de nuestro estudio. Más de un tercio de los contenidos emitidos por los informativos diarios se centran en el clima y en el tiempo, y su importancia hace que sean reseñados en los sumarios e incluso provoca la intervención en directo del meteorólogo de la cadena.

Por lo general, estas noticias suelen estar relacionadas con los sucesos y catástrofes asociados a los fenómenos meteorológicos, no obstante, se aprecia un creciente interés por los temas medioambientales, sobre todo de aquellos que tienen un cierto peso en la actualidad informativa, como son la protestas, informes o cumbres sobre el clima. No obstante, estas informaciones se centran, principalmente, en las consecuencias y no en las causas o soluciones, de forma que resultan poco relevantes.

Los resultados señalan que la titularidad de la cadena es un factor diferencial e influye en el número de noticias. Así pues, Televisión Española, debido su carácter público y de servicio al ciudadano, es la que ha dedicado más tiempo a informar sobre el medioambiente, sin embargo, es Telecinco la que emite un mayor número de noticias de informaciones relacionadas con este tema. La cadena de Mediaset realiza una cobertura homogénea en ambos periodos de estudio y abre el abanico a temas no marcados por la actualidad, tal es el caso de la rebelión verde, la contaminación o la presencia de plásticos en los distintos ámbitos de nuestra vida.

El estudio de las noticias referidas a la climatología se centra, fundamentalmente, en la acumulación de sucesos y de datos referidos a la catástrofe, es por ello, que la crónica es el género elegido por las tres cadenas para narrar desde el lugar de los acontecimientos la incidencia del fenómeno meteorológico. En este sentido, son frecuentes las conexiones en directo que aportan proximidad al hecho narrado, al tiempo que se incrementa la veracidad y credibilidad de lo contado. Telecinco es la cadena que utiliza esta fórmula en mayor medida, hasta en el $40 \%$ de sus piezas informativas.

Un aspecto que resulta interesante reseñar es la ausencia de entrevistas. Las tres cadenas descartan uno de los géneros más polivalentes del periodismo a la hora de aportar datos complementarios y centran su uso en la obtención de totales que se insertarán en la pieza informativa, lo cual resulta indicativo de la elevada pluralidad de opiniones presente en las noticias. Sin embargo, la mayoría de las declaraciones proceden de los afectados (60\%), quedando la postura de los expertos reducida a un $23 \%$, de forma que las televisiones optan por la descripción emotiva de los daños y las pérdidas frente a una exposición motivada de las causas que permita al receptor entender lo que ocurre en el mundo y formarse su propia opinión al respecto.

Pese a la escasa presencia de reportajes, que el relato informativo tenga una duración media superior a los tres minutos permite contextualizar la noticia y profundizar en las consecuencias. Ello apunta a una incipiente, y aún débil tendencia, a transmitir estas informaciones desde un punto de vista pedagógico que permita concienciar a los españoles en la necesidad de tomar medidas para paliar las consecuencias del cambio climático.

Los resultados de esta investigación apuntan a la necesidad de que las noticias aborden en mayor medida la vinculación de los desastres naturales con los desafíos medioambientales y que se presente una mayor atención a las soluciones frente a los devastadores impactos que generan. En este sentido, sería deseable que los informativos continúen explorando esta nueva vía informativa 
en la que las noticias relativas al tiempo se alejan de los mensajes catastrofistas o sensacionalistas para imponer una comunicación rigurosa que prioriza el encuadre medioambiental para sensibilizar y concienciar a la población sobre estos temas.

\section{Bibliografía}

Aemet (2019). Predicción estacional. Recuperado de http://www.aemet.es/es/idi/clima/ prediccion estacional

Águila Coghlan, J. C. (2015). La comunicación del Cambio Climático: análisis del discurso de los telediarios españoles sobre las Cumbres de Cancún y Durban”. (Tesis inédita de doctorado). Universidad Complutense de Madrid, Madrid. Recuperado de https://eprints.ucm.es/38010/

AIMC (2019). Entrega de resultados EGM $3^{a}$ ola 2019. Recuperado de https://www.aimc.es/ blog/entrega-resultados-egm-3a-ola-2019/

Bachetta, V. (2002). Perfil del periodista ambiental. Sala de Prensa, No 42 (2). Recuperado de http:// www.saladeprensa.org/art340.htm

Barlovento (2019). Análisis Audiencias TV: Octubre 2019. Recuperado de https://www. barloventocomunicacion.es/audiencias-mensuales/analisis-audiencia-tv-octubre-2019/

Boykoff, M.T (2010): Carbonundrums: the role of the media. En: Schneider, S.H., Rosencranz, A., Mastrandea, M.D. \& Kuntz-Duriseti, K. (Cords.) Climate change: science and policy. pp. 397-404. London: Island Press.

CMNUCC (1992). Convención Marco de las Naciones Unidas sobre el Cambio Climático. Recuperado de http://unfccc.int/resource/docs/convkp/convsp.pdf

Entman, R. M. (1993). Framing: towards clarification of a fractured paradigm. Journal of Communication, 43 (4), pp.51-58.

Fernández Reyes, R. (2010). La Sostenibilidad: una nueva etapa en el periodismo ambiental y en el periodismo en general. Delos, Vol.3, No8, pp. 1-17. Recuperado de http://www.eumed.net/rev/ delos $/ 08 /$ rfr.htm

Heras Hernández, F. (2013). La negación del cambio climático en España: percepciones sociales y nuevos tratamientos mediáticos. En Fernández Reyes, R. (Dir.). Medios de comunicación y cambio climático (pp. 155-171). Sevilla: Fénix Editora

Kindelán Amorrich, C. (2013). Percepción, información y comunicación para el cambio climático. Conocimiento en estudiantes universitarios. Tesis doctoral. Las Palmas de Gran Canaria. Recuperado de https://dialnet.unirioja.es/servlet/tesis? codigo $=86437$

Linés Escardó, A. (2010). Clima y cambio climático. Revista del Aficionado a la Meteorología, No26. Recuperado de http://www.divulgameteo.es/fotos/lecturas/Clima-CC-Linés.pdf

Maldonado, J.A. (2017). Breve historia de los espacios del tiempo en radio y televisión. Recuperado de https://aemetblog.es/2017/10/30/breve-historia-de-los-espacios-del-tiempo-en-radio-y- 
television/

Meira, P. A. (2008). Comunicar el Cambio Climático. Escenario social y líneas de acción. Madrid: Ministerio de Medio Ambiente y Medio Rural y Marino.

Mercado, M. (2013). El análisis del tratamiento informativo del cambio climático. En Fernández Reyes, R. (Dir.). Medios de Comunicación y Cambio Climático (pp. 123-134). Sevilla: Fénix Editora.

Moscovici, S. (1985). Psicología social I: influencia y cambio de actitudes. Cognición y desarrollo bumano. Barcelona: Paidós.

OPS (Organización Panamericana de la Salud) (2011). Manual periodístico para la cobertura ética de las emergencias y los desastres. Recuperado de https://fcic.periodistes.cat/wp-content/ uploads/2013/11/tragedias-periodistas.pdf

Ripple, W., Wolf. C., Newsome, T., Barnard P. y Moomaw, W. (2019). World Scientists Warning of a Climate Emergency. BioScience, Vol 69 (11). Recuperado de https://academic.oup.com/ bioscience/issue/69/11.

Rubira-García, R., Puebla-Martínez, B y Gelado-Marcos, R. (2018). Social Representations in Studying Information, Knowledge, and Meditations: A Critical Review. Soc. Sci., No 7, 256, pp.5-14

Sánchez, M. L., Morales, E. y Cáceres, M. D. (2012). La cobertura televisiva de la Cumbre de Cancún: agenda temática, discursos y fuentes en los informativos españoles. Index Comunicación, Vol. 2, N², pp. 113-128.

Scheufele, D. A. (1999). Framing as a theory of media effects. Journal of Communication, 49 (1), pp.103-122.

Semetko, H.A. y Valkenburg, P. M. (2000): Framing european politics: analysis of press and TV news. Journal of Communication, 50 (1), pp.93-109.

Tankard, J. W. (2001). The empirical approach to the study of media framing. En S. D. Reese, Stephen D., Oscar H. Gandy, y August E. Grant. (Eds.), Framing public life. Perspectives on media and our understanding of the social world. (pp.95-106). Mahwah, NJ: Lawrence Erlbaum Associates.

Teso, G. (2010): Televisión, publicidad y cambio climático. En León B. (Coord.), Informativos para la televisión del espectáculo. Sevilla-Zamora: Comunicación Social.

- (2016). Metodología aplicada para el análisis de las noticias televisivas sobre el cambio climático desde perspectivas cruzadas. En Libro de Actas del Seminario Internacional RESCLIMA I. Servizo de Publicacións e Intercambio Científico, Universidade de Santiago de Compostela, (pp. 51-71). Recuperado de https://www.ucm.es/data/cont/media/www/pag-16429/GemmaTesoRESCLIMA.pdf

- y Lozano, C. (2018). La comunicación del cambio climático en el medio televisivo en España. En Teso, G.; Fernández, R.; Gaitán, J.A.; Lozano, C. y Piñuel, J. L. (Eds). Comunicación para la Sostenibilidad: El cambio climático en los medios (pp. 72-139). Madrid: Fundación Alternativas. 
Vicente, M. y López, P. (2009). Resultados de la investigación en comunicación sobre framing: sólido avance y arranque de la especialidad en España. ZER Revista de Estudios en Comunicación, $\mathrm{N}^{\circ}$ 26, pp.13-34.

\section{Anexo}

7. 1 Duración de las noticias emitidas por TVE, Antena 3 y Telecinco entre los días 16 y 26 de septiembre.

\begin{tabular}{|r|r|r|r|r|r|r|r|r|r|r|r|r|}
\hline Septiembre & & 16 & 17 & 18 & 19 & 20 & 21 & 22 & 23 & 24 & 25 & 26 \\
\hline TVE & Sumario & $57^{\prime \prime}$ & $31^{\prime \prime}$ & $41^{\prime \prime}$ & $19^{\prime \prime}$ & $1^{\prime} 14^{\prime \prime}$ & $1^{\prime} 40^{\prime \prime}$ & $59^{\prime \prime}$ & $27^{\prime \prime}$ & $20^{\prime \prime}$ & $42^{\prime \prime}$ & \\
\hline & Noticia 1 & $7^{\prime} 42^{\prime \prime}$ & $2^{\prime} 22^{\prime \prime}$ & $3^{\prime} 42^{\prime \prime}$ & $4^{\prime} 03^{\prime \prime}$ & $1^{\prime} 38^{\prime \prime}$ & $3^{\prime} 43^{\prime \prime}$ & $2^{\prime} 54^{\prime \prime}$ & $1^{\prime} 53^{\prime \prime}$ & $1^{\prime} 10^{\prime \prime}$ & $1^{\prime} 47^{\prime \prime}$ & $1^{\prime} 20^{\prime \prime}$ \\
\hline & Previsión & $58^{\prime \prime}$ & $1^{\prime} 57^{\prime \prime}$ & $53^{\prime \prime}$ & & $5^{\prime} 09^{\prime \prime}$ & $1^{\prime} 10^{\prime \prime}$ & $52^{\prime \prime}$ & & & & \\
\hline & Noticia 2 & $6^{\prime} 16^{\prime \prime}$ & & $1^{\prime} 50^{\prime \prime}$ & & $1^{\prime} 12^{\prime \prime}$ & $1^{\prime} 44^{\prime \prime}$ & & $2^{\prime}$ & $1^{\prime} 12^{\prime \prime}$ & & $26^{\prime \prime}$ \\
\hline & Noticia 3 & & & & & $4^{\prime} 06^{\prime \prime}$ & $1^{\prime} 16^{\prime \prime}$ & & $1^{\prime} 53^{\prime \prime}$ & & & $1^{\prime} 20^{\prime \prime}$ \\
\hline & Noticia 4 & & & & & $2^{\prime} 12^{\prime \prime}$ & $2^{\prime} 58^{\prime \prime}$ & & $1^{\prime} 07^{\prime \prime}$ & & & \\
\hline & Previsión & & & & & $2^{\prime} 25^{\prime \prime}$ & & & & & & \\
\hline Total 1 & & $16^{\prime} 18^{\prime \prime}$ & $4^{\prime} 50^{\prime \prime}$ & $7^{\prime} 06^{\prime \prime}$ & $4^{\prime} 22^{\prime \prime}$ & $17^{\prime} 56^{\prime \prime}$ & $12^{\prime} 31^{\prime \prime}$ & $4^{\prime} 45^{\prime \prime}$ & $7^{\prime} 24^{\prime \prime}$ & $2^{\prime} 42^{\prime \prime}$ & $2^{\prime} 29^{\prime \prime}$ & $3^{\prime} 06^{\prime \prime}$ \\
\hline & & $30,52 \%$ & $8,49 \%$ & $13,30 \%$ & $7,96 \%$ & $33,13 \%$ & $23,22 \%$ & $8,39 \%$ & $13,66 \%$ & $4,56 \%$ & $4,32 \%$ & $5,77 \%$ \\
\hline
\end{tabular}

\begin{tabular}{|r|r|r|r|r|r|r|r|r|r|r|r|r|}
\hline Septiembre & & 16 & 17 & 18 & 19 & 20 & 21 & 22 & 23 & 24 & 25 & 26 \\
\hline Telecinco & Sumario & $1^{\prime} 10^{\prime \prime}$ & $45^{\prime \prime}$ & $43^{\prime \prime}$ & $46^{\prime \prime}$ & $2^{\prime} 20^{\prime \prime}$ & $42^{\prime \prime}$ & $49^{\prime \prime}$ & & $24^{\prime \prime}$ & $20^{\prime \prime}$ & \\
\hline & Noticia 1 & $11^{\prime} 10^{\prime \prime}$ & $9^{\prime} 49^{\prime \prime}$ & $4^{\prime} 59^{\prime \prime}$ & $3^{\prime} 14^{\prime \prime}$ & $28^{\prime \prime}$ & $2^{\prime} 49^{\prime \prime}$ & $1^{\prime} 50^{\prime \prime}$ & $1^{\prime} 04^{\prime \prime}$ & $11^{\prime \prime}$ & $1^{\prime} 53^{\prime \prime}$ & $35^{\prime \prime}$ \\
\hline & Previsión & & & & & $1^{\prime} 27^{\prime \prime}$ & & & $1^{\prime} 15^{\prime \prime}$ & & & \\
\hline & Noticia 2 & $2^{\prime} 55^{\prime \prime}$ & & & & $2^{\prime} 44^{\prime \prime}$ & $58^{\prime \prime}$ & & $4^{\prime} 21^{\prime \prime}$ & $1^{\prime \prime}$ & $1^{\prime} 20^{\prime \prime}$ & $1^{\prime} 23^{\prime \prime}$ \\
\hline & Noticia 3 & & & & & $1^{\prime} 55^{\prime \prime}$ & $20^{\prime \prime}$ & & & $8^{\prime \prime}$ & & \\
\hline & Noticia 4 & & & & & $1^{\prime} 26^{\prime \prime}$ & & & & & & \\
\hline & Previsión & & & & & & & & & & & \\
\hline & Noticia 5 & & & & & $2^{\prime} 26^{\prime \prime}$ & & & & & & \\
\hline & Noticia 6 & & & & & $2^{\prime} 30^{\prime \prime}$ & & & & & & \\
\hline Total 1 & & $15^{\prime} 15^{\prime \prime}$ & $10^{\prime} 34^{\prime \prime}$ & $5^{\prime} 42^{\prime \prime}$ & $4^{\prime}$ & $14^{\prime} 18^{\prime \prime}$ & $4^{\prime} 49^{\prime \prime}$ & $2^{\prime} 39^{\prime \prime}$ & $6^{\prime} 40^{\prime \prime}$ & $2^{\prime} 47^{\prime \prime}$ & $3^{\prime} 33^{\prime \prime}$ & $1^{\prime} 58^{\prime \prime}$ \\
\hline & & $44,55 \%$ & $30,41 \%$ & $15,94 \%$ & $11,76 \%$ & $41,70 \%$ & $13,20 \%$ & $7,02 \%$ & $18,82 \%$ & $7,26 \%$ & $9,79 \%$ & $4,64 \%$ \\
\hline
\end{tabular}

\begin{tabular}{|r|r|r|r|r|r|r|r|r|r|r|r|r|}
\hline Septiembre & & 16 & 17 & 18 & 19 & 20 & 21 & 22 & 23 & 24 & 25 & 26 \\
\hline Telecinco & Sumario & $1^{\prime} 10^{\prime \prime}$ & $45^{\prime \prime}$ & $43^{\prime \prime}$ & $46^{\prime \prime}$ & $2^{\prime} 20^{\prime \prime}$ & $42^{\prime \prime}$ & $49^{\prime \prime}$ & & $24^{\prime \prime}$ & $20^{\prime \prime}$ & \\
\hline & Noticia 1 & $1^{\prime} 1^{\prime \prime} 10^{\prime \prime}$ & $9^{\prime} 49^{\prime \prime}$ & $4^{\prime} 59^{\prime \prime}$ & $3^{\prime} 14^{\prime \prime}$ & $28^{\prime \prime}$ & $2^{\prime} 49^{\prime \prime}$ & $1^{\prime} 50^{\prime \prime}$ & $1^{\prime} 04^{\prime \prime}$ & $1^{\prime \prime}$ & $1^{\prime} 53^{\prime \prime}$ & $35^{\prime \prime}$ \\
\hline & Previsión & & & & & $1^{\prime} 27^{\prime \prime}$ & & & $1^{\prime} 15^{\prime \prime}$ & & & \\
\hline & Noticia 2 & $2^{\prime} 55^{\prime \prime}$ & & & & $2^{\prime} 44^{\prime \prime}$ & $58^{\prime \prime}$ & & $4^{\prime} 21^{\prime \prime}$ & $14^{\prime \prime}$ & $1^{\prime} 20^{\prime \prime}$ & $1^{\prime} 23^{\prime \prime}$ \\
\hline & Noticia 3 & & & & & $1^{\prime} 55^{\prime \prime}$ & $20^{\prime \prime}$ & & & $58^{\prime \prime}$ & & \\
\hline & Noticia 4 & & & & $1^{\prime} 26^{\prime \prime}$ & & & & & & \\
\hline & Previsión & & & & & & & & & & & \\
\hline & Noticia 5 & & & & $2^{\prime} 26^{\prime \prime}$ & & & & & & \\
\hline & Noticia 6 & & & & & $2^{\prime} 30^{\prime \prime}$ & & & & & & \\
\hline Total 1 & & $15^{\prime} 15^{\prime \prime}$ & $10^{\prime} 34^{\prime \prime}$ & $5^{\prime} 42^{\prime \prime}$ & $4^{\prime}$ & $14^{\prime} 18^{\prime \prime}$ & $4^{\prime} 49^{\prime \prime}$ & $2^{\prime} 39^{\prime \prime}$ & $6^{\prime} 40^{\prime \prime}$ & $2^{\prime} 47^{\prime \prime}$ & $3^{\prime} 33^{\prime \prime}$ & $1^{\prime} 58^{\prime \prime}$ \\
\hline & & $44,55 \%$ & $30,41 \%$ & $15,94 \%$ & $11,76 \%$ & $41,70 \%$ & $13,20 \%$ & $7,02 \%$ & $18,82 \%$ & $7,26 \%$ & $9,79 \%$ & $4,64 \%$ \\
\hline
\end{tabular}


7. 2 Duración de las noticias emitidas por TVE, Antena 3 y Telecinco entre los días 7 y 17 de octubre.

\begin{tabular}{|r|r|r|r|r|r|r|r|r|r|r|r|r|}
\hline Octubre & & 7 & 8 & 9 & 10 & 11 & 12 & 13 & 14 & 15 & 16 & 17 \\
\hline TVE & Sumario 1 & & $1^{\prime} 10^{\prime \prime}$ & $52^{\prime \prime}$ & $27^{\prime \prime}$ & $58^{\prime \prime}$ & $18^{\prime \prime}$ & $20^{\prime \prime}$ & $18^{\prime \prime}$ & $18^{\prime \prime}$ & & \\
\hline & Sumario 2 & & & & & & & $21^{\prime \prime}$ & & & & \\
\hline & Sumario 3 & & & & & & $16^{\prime \prime}$ & & & & \\
\hline & Sumario 4 & & & & & & $11^{\prime \prime}$ & & & & \\
\hline & Noticia 1 & $2^{\prime} 56^{\prime \prime}$ & $2^{\prime} 53^{\prime \prime}$ & $2^{\prime} 47^{\prime \prime}$ & $1^{\prime} 25^{\prime \prime}$ & $19^{\prime \prime}$ & $1^{\prime} 58^{\prime \prime}$ & $1^{\prime} 07^{\prime \prime}$ & $2^{\prime} 05^{\prime \prime}$ & & $54^{\prime \prime}$ \\
\hline & Previsión & & $1^{\prime} 43^{\prime \prime}$ & & & $1^{\prime} 15^{\prime \prime}$ & $19^{\prime \prime}$ & & & & & \\
\hline & Noticia 2 & & & & & & $1^{\prime} 02^{\prime \prime}$ & $3^{\prime} 11^{\prime \prime}$ & & $1^{\prime} 31^{\prime \prime}$ & & \\
\hline & Noticia 3 & & & & & $3^{\prime \prime}$ & $17^{\prime \prime \prime}$ & & & & \\
\hline & Noticia 4 & & & & & & $49^{\prime \prime}$ & & & & \\
\hline & Previsión & & & & & & & $45^{\prime \prime}$ & & & & \\
\hline Total 1 & & & $5^{\prime} 49^{\prime \prime}$ & $3^{\prime} 46^{\prime \prime}$ & $3^{\prime} 13^{\prime \prime}$ & $3^{\prime} 28^{\prime \prime}$ & $2^{\prime} 11^{\prime \prime}$ & $8^{\prime} 35^{\prime \prime}$ & $1^{\prime} 25^{\prime \prime}$ & $3^{\prime} 54^{\prime \prime}$ & & $54^{\prime \prime}$ \\
\hline & & & $\mathbf{1 0 , 3 5 \%}$ & $6,52 \%$ & $\mathbf{5 , 9 0 \%}$ & $6,18 \%$ & $3,98 \%$ & $\mathbf{1 7 , 0 0 \%}$ & $\mathbf{2 , 3 5 \%}$ & $\mathbf{6 , 6 7 \%}$ & & $1,01 \%$ \\
\hline
\end{tabular}

\begin{tabular}{|c|c|c|c|c|c|c|c|c|c|c|c|c|}
\hline Octubre & & 7 & 8 & 9 & 10 & 11 & 12 & 13 & 14 & 15 & 16 & 17 \\
\hline \multirow[t]{8}{*}{ Antena 3} & Sumario & & & & $17^{\prime \prime}$ & $13^{\prime \prime}$ & $16^{n}$ & $17^{\mathrm{B}}$ & $18^{\prime \prime}$ & & & \\
\hline & Sumario & & & & & & & $17^{\mathrm{B}}$ & & & & \\
\hline & Noticia 1 & & $2^{\prime}$ & & 2'14" & 1'41" & $48^{\prime \prime}$ & $2^{\prime} 42^{\prime \prime}$ & $2^{\prime} 43^{\prime \prime}$ & & & \\
\hline & Previsión & & & & & $14^{\prime \prime}$ & & & & & & \\
\hline & Noticia 2 & & & & & & $27^{\mathrm{B}}$ & $4^{\prime} 04^{\prime \prime}$ & $15^{\prime \prime}$ & & & \\
\hline & Noticia 3 & & & & & & $1^{\prime} 08^{\prime \prime}$ & & $14^{\prime \prime}$ & & & \\
\hline & Noticia 4 & & & & & & $1^{\prime} 51^{\prime \prime}$ & & & & & \\
\hline & Previsión & & & & & 1'11" & & & & & & \\
\hline \multirow[t]{2}{*}{ Total 1} & & & $2^{\prime}$ & & $2^{\prime} 31^{\prime \prime}$ & 3'19" & $4^{\prime} 30^{\prime \prime}$ & $7^{\prime} 18^{\prime \prime}$ & 3'38" & & & \\
\hline & & & $5,80 \%$ & & $6,79 \%$ & $9,38 \%$ & $12,64 \%$ & $21,11 \%$ & $9,94 \%$ & & & \\
\hline
\end{tabular}

\begin{tabular}{|r|r|r|r|r|r|r|r|r|r|r|r|r|}
\hline Octubre & & 7 & 8 & 9 & 10 & 11 & 12 & 13 & 14 & 15 & 16 & 17 \\
\hline Telecinco & Sumario & $2^{\prime} 02^{\prime \prime}$ & $25^{\prime \prime}$ & & $29^{\prime \prime}$ & $37^{\prime \prime}$ & $20^{\prime \prime}$ & $34^{\prime \prime}$ & & & & \\
\hline & Sumario & & $28^{\prime \prime}$ & & & & & $37^{\prime \prime}$ & & & & \\
\hline & Noticia 1 & $1^{\prime} 24^{\prime \prime}$ & & $1^{\prime} 21^{\prime \prime}$ & $1^{\prime} 36^{\prime \prime}$ & $1^{\prime} 38^{\prime \prime}$ & $28^{\prime \prime}$ & $17^{\prime \prime}$ & $59^{\prime \prime}$ & $2^{\prime} 50^{\prime \prime}$ & $43^{\prime \prime}$ & $1^{\prime} 47^{\prime \prime}$ \\
\hline & Previsión & & & & & & & & & & & \\
\hline & Noticia 2 & & $2^{\prime} 05^{\prime \prime}$ & $1^{\prime} 50^{\prime \prime}$ & $52^{\prime \prime}$ & & $2^{\prime} 29^{\prime \prime}$ & $1^{\prime \prime} 51^{\prime \prime}$ & $2^{\prime} 03^{\prime \prime}$ & $20^{\prime \prime}$ & & \\
\hline & Noticia 3 & & $1^{\prime} 18^{\prime \prime}$ & $1^{\prime} 48^{\prime \prime}$ & $2^{\prime} 26^{\prime \prime}$ & & & $2^{\prime} 13^{\prime \prime}$ & $50^{\prime \prime}$ & & & \\
\hline & Noticia 4 & & $2^{\prime}$ & $38^{\prime \prime}$ & & & & $34^{\prime \prime}$ & $47^{\prime \prime}$ & & & \\
\hline & Noticia 5 & & $19^{\prime \prime}$ & & & & & $1^{\prime} 43^{\prime \prime}$ & & & & \\
\hline & Noticia 6 & & $25^{\prime \prime}$ & & & & & & & & & \\
\hline & Previsión & & & & & & & & & & & \\
\hline Total 1 & & $3^{\prime} 26^{\prime \prime}$ & $7^{\prime}$ & $5^{\prime} 37^{\prime \prime}$ & $5^{\prime} 23^{\prime \prime}$ & $2^{\prime} 15^{\prime \prime}$ & $3^{\prime} 17^{\prime \prime}$ & $7^{\prime} 49^{\prime \prime}$ & $4^{\prime} 40^{\prime \prime}$ & $3^{\prime} 10^{\prime \prime}$ & $43^{\prime \prime}$ & $1^{\prime} 47^{\prime \prime}$ \\
\hline & & $9,58 \%$ & $20,58 \%$ & $15,79 \%$ & $15,38 \%$ & $6,32 \%$ & $9,32 \%$ & $22,02 \%$ & $12,94 \%$ & $9,11 \%$ & $1,26 \%$ & $4,32 \%$ \\
\hline
\end{tabular}


MHCJ Vol. 11 (2) | Año 2020 - Artículo n¹6 (167) - Páginas 315 a 336 - mhjournal.org

\section{(c) $\underset{\mathrm{BY}}{\mathrm{BP}}$}

Licencia Creative Commons

Miguel Hernández Communication Journal

mhjournal.org

\section{Cómo citar este texto:}

Marián Alonso González (2020): Tiempo y medio ambiente como ejes noticiosos en los informativos de TVE.

Antena 3 y Telecinco, en Miguel Hernández Communication Journal, Vol. 11 (2), pp. 315 a 336 . Universidad Miguel Hernández, UMH (Elche-Alicante). DOI: http://dx.doi.org/10.21134/mhcj.v11i0.337 